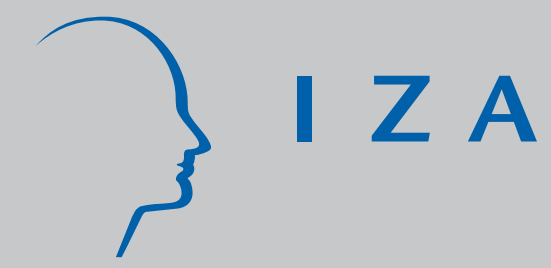

IZA DP No. 83

Female Labour Supply, Flexibility of Working Hours, and J ob Mobility in the Netherlands

Rob Euwals

December 1999 


\title{
Female Labour Supply, Flexibility of Working Hours, and Job Mobility in the Netherlands
}

\author{
Rob Euwals \\ IZA, Bonn, Germany
}

Discussion Paper No. 83
December 1999

\author{
IZA \\ P.O. Box 7240 \\ D-53072 Bonn \\ Germany \\ Tel.: +49-228-3894-0 \\ Fax: +49-228-3894-210 \\ Email: iza@iza.org
}

This Discussion Paper is issued within the framework of IZA's research area Mobility and Flexibility of Labor Markets. Any opinions expressed here are those of the author(s) and not those of the institute. Research disseminated by IZA may include views on policy, but the institute itself takes no institutional policy positions.

The Institute for the Study of Labor (IZA) in Bonn is a local and virtual international research center and a place of communication between science, politics and business. IZA is an independent, nonprofit limited liability company (Gesellschaft mit beschränkter Haftung) supported by the Deutsche Post AG. The center is associated with the University of Bonn and offers a stimulating research environment through its research networks, research support, and visitors and doctoral programs. IZA engages in (i) original and internationally competitive research in all fields of labor economics, (ii) development of policy concepts, and (iii) dissemination of research results and concepts to the interested public. The current research program deals with (1) mobility and flexibility of labor markets, (2) internationalization of labor markets and European integration, (3) the welfare state and labor markets, (4) labor markets in transition, (5) the future of work, (6) project evaluation and (7) general labor economics.

IZA Discussion Papers often represent preliminary work and are circulated to encourage discussion. Citation of such a paper should account for its provisional character. 
IZA Discussion Paper No. 83

December 1999

\section{ABSTRACT \\ Female Labour Supply, Flexibility of Working Hours, and Job Mobility in the Netherlands}

In the empirical literature on labour supply, several static models are developed to incorporate constraints on working hours. These models do not address to what extent working hours are constrained within jobs, and to what extent working hours can be adjusted by means of changing employer. The aim of this paper is to measure the flexibility of working hours within and between jobs by utilizing subjective information on individual preferences to adjustments in working hours. The potential endogeneity of both the subjective information and job mobility will be taken into account. Furthermore, we argue that the Netherlands is an interesting country for the study of working hour flexibility, as part-time employment is fairly common. Empirical analysis based on a sample of employed women in the Dutch SocioEconomic Panel (1987-1989) shows, however, that the flexibility of working hours within jobs is low. Job mobility is a means of adjustment in working hours mainly for women who want to work more hours.

JEL Classification: C20, J22, J60

Keywords: : Labour supply, hours restrictions, job mobility

Rob Euwals

IZA

P.O. Box 7240

D-53072 Bonn

Germany

Tel.: +49228 3894302

Fax: +492283894210

Email: Euwals@iza.org

\footnotetext{
*Statistics Netherlands (CBS) is gratefully acknowledged for providing the data. I thank Rob Alessie, Kurt Brannas, Angelika Eymann, Vassilis Hajivassiliou, François Laisney, Bertrand Melenberg, Arthur van Soest, Melanie Ward and the participants of the seminars at IZA, Tilburg University and the EALE 1999, Regensburg, for valuable comments and helpful discussions.
} 


\section{Introduction}

The empirical literature on labour supply traditionally assumes that workers can choose their working hours freely and without costs, up to a maximum equal to the time endowment. The potential invalidity of this assumption is acknowledged, but it is often made for the tractability of the econometric model. As a result, several models have been developed to incorporate restrictions on working hours. The first generation of models extended the traditional censored regression model for working hours by additionally allowing for censoring due to over- and underemployment, and involuntary unemployment. See, for instance, the seminal articles by Moffitt (1982), Ham (1982) and Blundell et al. (1987). The second generation of models extended the structural utility optimisation model by introducing job offers concerning hours of work. See, for instance, the articles by Van Soest et al. (1990) and Dickens and Lundberg (1993). A conclusion of these studies is that incorporating restrictions on working hours significantly improves the empirical fit of the model. This can be interpreted as empirical evidence for the intuitively obvious conjecture that working hours cannot be chosen freely.

A peculiar component of the models discussed above is that they are static. Therefore they are not suitable to distinguish between the different "ingredients" needed for the existence of hours restrictions on the labour market. First, there has to be a lack of possibilities to adjust working hours with the same employer, e.g. within a job. But this alone does not necessarily imply that the individuals are not on their labour supply curve, as they might change to another employer, which offers them their preferred working hours. A second necessary ingredient for the existence of hours restrictions in the labour market are mobility costs.

So, although the existence of hours restrictions in the labour market cannot be questioned, it is still an open and intriguing question how tight these restrictions are. One might also ask to what extent job mobility is a means to adjust working hours. Altonji and Paxson $(1986,1992)$ look at the adjustment of working hours over time, and distinguish between those individuals who stay in their job, and those who change job. Based on the US Panel Study of Income Dynamics, they conclude that working hours of married women are two to four times more variable across jobs than within jobs. In their second article, they correct for the potential endogeneity of job mobility. This does not change their main conclusion: hours vary significantly more in the case of job mobility. Based on the US National Longitudinal Survey of Youth, Matinez-Granado (1999) draws the same conclusions for prime age men. 
The novelty of the study in this paper is that by formulating a latent variable model for the preferred working hours, and by using subjective information on these preferences to identify the model, we are able to get point estimates for the flexibility of working hours within jobs. This is in contrast to the previous authors, who have only been able to conclude on the flexibility of working hours within jobs, relative to the adjustments between jobs.

This study concentrates on female labour supply in the Netherlands. The experience of the Netherlands is interesting, as the share of part-time jobs to total employment is high. Furthermore, the distribution of working is relatively even across the hour spectrum. So if we are seeking for flexibility in working hours, the Netherlands might be a good candidate to find this. We decide to concentrate on female labour supply only, as in the Netherlands the share of part-time jobs among men is not high (although still high compared to other countries). For the empirical analysis in this paper we use the Dutch Socio-Economic Panel (DSEP), which contains subjective data on preferred working hours. Using the same data, Euwals et al. (1998) show that subjective data have good predictive powers. Conditional on actual working hours, the subjective data on desired working hours successfully predict the next year's working hours. The subjective data on desired working hours therefore contain information on individual preferences, as individuals do really adjust according to these data. The explicit goal of this latter study was to test the relationship without making additional assumptions, and without having a structural model in mind. Conclusions in a more structural and economic sense, for instance on the size of the adjustments within and between jobs, could therefore not be made. That is the contribution of the current paper.

The remainder of the paper is organised as follows. Section 2 discusses the Dutch labour market. Section 3 presents questions on working hours in the DSEP. Section 4 introduces an empirical model for job mobility and hours adjustments within and between jobs. Section 5 presents the data in the DSEP. Section 6 discusses the results, and section 7 concludes.

\section{The Netherlands}

In terms of labour force participation and part-time employment, the Netherlands does not hold an average position among the EC and OECD countries. Table 1 shows that female labour force participation has increased quite strongly over recent decades; in the 1970s the participation rate in the Netherlands was below the average OECD-rate, but by the 1990s the rate for the Netherlands has been above the average OECD-rate. During the period under 
consideration in this paper, that is the end of the 1980s the Dutch female labour force participation rate was still below the average OECD-level. Important for the interpretation of results on the possibilities of employed woman to adjust working hours within and between jobs, is the unemployment situation. A high unemployment rate results in a bad negotiation position for employees. As in most European countries, the Dutch unemployment rate was high in the 1980 s, see table 1.

Part-time employment is fairly common in the Netherlands, especially for women. At the end of the 1980s about 50 percent of employed women had a part-time job. This percentage increased further in the 1990s. Based on a sample of employed women from the DSEP 1987, figure 1 shows that the histogram for working hours is not particularly spiked at the point of the standard full-time job of 36 to 40 hours per week. Few women do paid overtime work, and many have a part-time job. In contrast to this, Euwals et al. (1998) show that the working hours distribution for men is spiked at the point of the standard full-time job.

\section{Table 1: labour force participation, unemployment and part-time employment}

\begin{tabular}{|c|c|c|c|c|c|c|}
\hline & \multicolumn{3}{|c|}{ Men } & \multicolumn{3}{|c|}{ Women } \\
\hline & Netherl. & Germany & USA & Netherl. & Germany & USA \\
\hline \multicolumn{7}{|c|}{ participation } \\
\hline 1973 & 85.5 & 89.6 & 86.2 & 29.2 & 50.3 & 51.1 \\
\hline 1983 & 77.3 & 82.6 & 84.6 & 40.3 & 52.5 & 61.8 \\
\hline 1990 & 79.6 & 81.3 & 85.8 & 53.0 & 57.0 & 68.2 \\
\hline 1994 & 79.8 & 80.1 & 84.3 & 57.4 & 61.1 & 69.4 \\
\hline 1996 & 80.0 & 79.7 & 84.3 & 59.6 & 61.5 & 70.1 \\
\hline
\end{tabular}

\begin{tabular}{|c|c|c|c|c|c|c|}
\hline 1983 & 10.9 & 7.3 & 9.9 & 13.7 & 8.8 & 9.2 \\
\hline 1990 & 5.7 & 5.4 & 5.7 & 10.9 & 7.5 & 5.6 \\
\hline 1994 & 6.6 & 7.3 & 6.2 & 8.1 & 10.0 & 6.1 \\
\hline 1996 & 5.3 & 8.1 & 5.4 & 8.1 & 9.8 & 5.1 \\
\hline
\end{tabular}

\begin{tabular}{|c|c|c|c|c|c|c|}
\hline 1983 & 5.6 &.-- & 9.1 & 44.7 &.-- & 22.9 \\
\hline 1990 & 13.3 & 1.8 & 8.3 & 50.8 & 29.6 & 20.0 \\
\hline 1994 & 10.7 & 2.7 & 8.0 & 53.5 & 27.9 & 19.5 \\
\hline 1996 & 10.8 & 3.3 & 7.7 & 55.2 & 29.8 & 19.1 \\
\hline
\end{tabular}




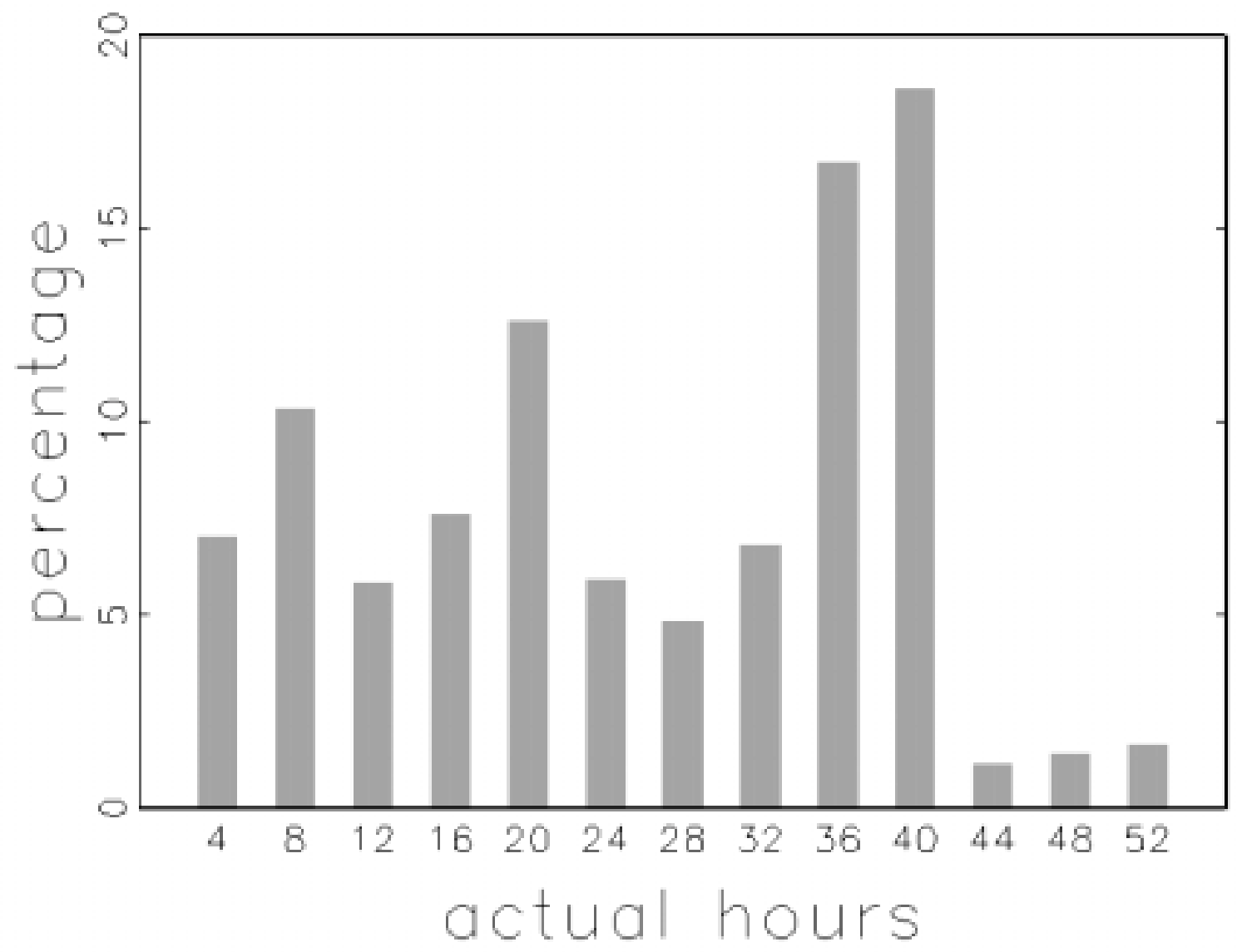

Figure 1: Actual hours distribution for employed women, DSEP 1987.

Actual hours per week, classification $h:(h-1, h+2)$ except 4:(1,6) and 52:(51,80)

The relatively even distribution of working hours makes the Dutch labour market look flexible in terms of working hours. In this paper we investigate whether the flexibility in working hours also holds within jobs; or in other words, whether employed women can adjust their working hours in the direction they want. At the end of the 1980s, there are no institutional arrangements that would make the outcome of this study obvious. ${ }^{2}$

\footnotetext{
${ }^{2}$ In recent years the flexibility of working hours within jobs has become a serious topic in the Dutch political discussion. But has not (yet) lead to legislation.
} 


\section{Measurement}

The data are drawn from the October waves of the 1987, 1988 and 1989 Dutch SocioEconomic Panel (DSEP), collected by Statistics Netherlands. The DSEP has existed since 1984. Only these years however are suitable for the analysis of actual and desired working hours. For the other years, desired hours are only asked to new participants in the panel, and to participants who chance jobs. And our analysis requires the desired working hours for all employees. The questions on the actual and desired hours of work are as follows:

Ia How many hours per week do you work in your job, or jobs?

- Do not include travelling time to and from your work.

- Include overtime only if it is paid.

Ib Are you satisfied with this number of working hours, or would you prefer to work more or fewer hours per week? Possible answers:

1) I am satisfied with the number of working hours $\quad \Rightarrow$ stop

2) I prefer to work more $\quad \Rightarrow$ question Ic

3) I prefer to work less. $\quad \Rightarrow$ question Ic

Ic If, in the previous question, you were not satisfied with your working hours, how many hours would you then like to work?

The answers to questions Ia to Ic by individual $\mathrm{i}$ in year $\mathrm{t}$ are denoted by $h a_{i t}, s_{i t}$, and $h d_{i t}$, respectively. Actual hours $h a_{i t}$ and desired hours $h d_{i t}$ are measured as hours per week. Based upon question $\mathrm{Ib}$, we define the variable $s_{i t}$ (satisfied): $s_{i t}=0$ if individual $\mathrm{i}$ is satisfied with the number of working hours in period $\mathrm{t}$ (answer 1), $s_{i l} \equiv 1$ if the individual wants to work more (answer 2) and $s_{i t}=-1$ if the individual wants to work less (answer 3). Only for respondents answering question Ic, $s_{i t}$ is not equal to zero. For those with $s_{i t}=0$, desired hours $h d_{i t}$ are set equal to actual hours $h a_{i t}$. The qualitative information $s_{i t}$ is similar to that in, for example, the PSID. Underemployment corresponds to $s_{i t}=1$, overemployment corresponds to $s_{i t}=-1$. The quantitative information in $h d_{i t}$ is more detailed: $s_{i t}$ can be retrieved from $h d_{i t}-h a_{i t}$. 
The actual hours $h a_{i t}$ can be referred to as objective data, as they relate to an objectively measurable fact. They can also be referred to as revealed preference, as they are the result of individual optimisation behaviour, given the choices the individual has. In contrast to this, the desired hours $h d_{i t}$ relate to preferences in the case that an individual is not restricted in the choice of working hours. These preferences are only conceived in the minds of the individuals, ands are not objectively measurable. The literature refers to this kind of data as a stated preference or as subjective data.

The use of stated preferences is not without criticism in economic science. An early example of this kind of data can be found in the U.S. Survey of Consumer Finances, which already in the 1940s contained information on, for instance, income expectations and buying intentions. These data were criticised by several authors; for instance Juster (1964) concluded that data on buying intentions have little predictive power. This criticism led to the common methodology that statistical inference should be based on realised behaviour only. In the last decades however empirical literature has revealed a fundamental problem: the parameters of interest are often badly identified. The common solution of making additional assumptions turned not to be that fruitful; they are often rejected by formal tests. Therefore several authors return to the idea that subjective data might be useful for the better identification of economic models. So following the recent literature by, for instance, Börsch-Supan et al. (1993), BenAkiva et al. (1998) and Ben-Akiva et al. (1999), this study will treat the stated preference a result of an underlying latent preference.

To investigate the informational content of the subjective data on the desired working hours, Euwals et al. (1998) test whether conditional on the actual working hours $h a_{i t}$, the desired hours $h d_{i t}$ have a predictive power for the next year's working hours $h a_{i t+l}$. The study concludes that the predictive power of the desired working hours holds for women, but hardly for men. The study also shows that for women the predictive power holds conditional on both the actual working hours $h a_{i t}$, and satisfaction $s_{i t}$. This means that on top of question Ib, question Ic gives additional information. These results show that the subjective data on desired working hours do contain information on individual preferences, as individuals do indeed adjust according to these data. The explicit goal of the study was to test this without making additional assumptions, and without having an underlying economic model in mind. In contrast to this, the contribution of this study will be to draw structural conclusions on the flexibility of the working hours within and between jobs. 


\section{Model}

In this section we develop an empirical model to measure the flexibility of working hours within jobs, taking job-mobility into account. We are going to relate dissatisfaction with actual working hours, measured by the difference $h d_{i t}-h a_{i t}$, to job-mobility and to adjustments in working hours from time $\mathrm{t}$ to time $\mathrm{t}+1 .^{3}$ The underlying assumption of this approach is that adjustments in working hours over time are slow, and that the working hours at time $t+1$ are at least partly determined by the desired working hours at time t. This assumption is supported by Euwals et al. (1998), who show for the same data that desired working hours do indeed have a predictive power for the next year's working hours.

A potential problem that we take into account is that the subjective data on the desired working hours do not necessarily coincide with the 'true' desired hours of the individuals. We will refer to the subjectively measured desired hours as the observed desired hours, $h d_{i t}$, which might be an imperfect measure of the true desired hours, $h d_{i t}{ }^{*}$. Furthermore, women who are not satisfied with their working hours, and who are not able to adjust these within their job, are more likely to change job. This makes job-mobility endogenous. We therefore model:

$$
\begin{array}{rlll}
q_{i t}{ }^{*} & =X_{i t}{ }^{\prime} \alpha+f\left(h d_{i t}{ }^{*}-h a_{i t} ; \beta\right)+\varepsilon_{i}{ }^{q}+\varepsilon_{i t}{ }^{q} & \text { (Job Mobility) } \\
q_{i t} & =1 \quad \text { if } q_{i t}{ }^{*} \geq 0 & & \text { (job-movers from time } \mathrm{t} \text { to } \mathrm{t}+1) \\
& =0 \quad \text { if } q_{i t}{ }^{*}<0 & & \text { (job-stayers from time } \mathrm{t} \text { to } \mathrm{t}+1)
\end{array}
$$

with $X_{i t}$ a vector of exogenous variables, including the actual working hours $h a_{i t}$, and $\alpha$ and $\beta$ parameter-vectors. Furthermore, $\varepsilon_{i}^{q}$ and $\varepsilon_{i t}{ }^{q}$ are an individual effect and a random term, respectively. Function $f$ concerns the impact of dissatisfaction with the working hours $h a_{i t}$, and will allow for different effects for women who want to work more, and for women who want to work less hours per week:

$$
f\left(h d_{i t}{ }^{*}-h a_{i t} ; \beta\right)=P\left(h d_{i t}{ }^{*}-h a_{i t} \geq 0\right)\left(h d_{i t}{ }^{*}-h a_{i t}\right) \beta^{p}+P\left(h d_{i t}{ }^{*}-h a_{i t}<0\right)\left(h d_{i t}{ }^{*}-h a_{i t}\right) \beta^{n}
$$

\footnotetext{
${ }^{3}$ A more structural approach would be to assume that women optimise their utility over next year's income and working hours. However, the empirical implementation of this would need additional assumptions on the jobopportunities at time $t+1$, as these are not observed in the data. The approach in the paper avoids this problem.
} 
The central issue of this study is the extent in which women are able to adjust their working hours within and between jobs. Define the change in working hours $\Delta h a_{i t}=h a_{i t+1}-h a_{i t}$ :

$$
\begin{aligned}
\Delta h a_{i t} & =Z_{i t}{ }^{\prime} \gamma+g\left(h d_{i t}{ }^{*}-h a_{i t} ; \delta_{i t}\right)+\varepsilon_{i t}{ }^{a} \\
\delta_{i t} & =\delta_{s}\left(1-Q_{i t}\right)+\delta_{m} Q_{i t}
\end{aligned}
$$

(Hours Adjustment)

with $Z_{i t}$ a vector of exogenous variables, including the actual working hours $h a_{i t}$, and $\alpha, \delta_{s}$ and $\delta_{m}$ parameter vectors. The idea behind the variable $\delta_{i t}$ is to allow for different adjustment levels for job-movers and job-stayers. Furthermore, $\varepsilon_{i t}{ }^{a}$ concerns a random term. An individual term is not included, as this would imply a constant rise or fall in the actual hours. Function $g$ concerns the impact of dissatisfaction with actual working hours $h a_{i t}$, and will allow for different effects for women who want to work more and who want to work less:

$g\left(h d_{i t}{ }^{*}-h a_{i t} ; \delta_{i t}\right)=P\left(h d_{i t}{ }^{*}-h a_{i t} \geq 0\right)\left(h d_{i t}{ }^{*}-h a_{i t}\right) \delta_{i t}{ }^{p}+P\left(h d_{i t}{ }^{*}-h a_{i t}<0\right)\left(h d_{i t}{ }^{*}-h a_{i t}\right) \delta_{i t}{ }^{n}$

with $\delta_{i t}{ }^{x} \quad=\delta_{s}^{x}\left(1-Q_{i t}\right)+\delta_{m}{ }^{x} Q_{i t}, \quad x=p, n$

Equations (1) and (2) model the effect of the true desired hours, $h d_{i t}{ }^{*}$, on realised labour market behaviour. The next step is to model how the true desired hours, $h d_{i t}{ }^{*}$ relate to the observed desired hours, $h d_{i t}$. Besides the fact that we allow for measurement error, we will allow for the fact that respondents might be influenced by their actual working hours when answer such questions. We assume that the observed desired hours are a weighted average:

$$
h d_{i t} \quad=\lambda h d_{i t}{ }^{*}+(1-\lambda) h a_{i t}+\varepsilon_{i}^{d}+\varepsilon_{i t}{ }^{d}
$$

(Measurement)

with $\lambda$ a parameter, and $\varepsilon_{i}^{d}$ and $\varepsilon_{i t}{ }^{d}$ an individual effect and an random term, respectively. The last step is to model the true desired hours:

$$
h d_{i t}^{*}=D_{i t}{ }^{\prime} \theta+\xi_{i}+\xi_{i t}
$$




\begin{tabular}{|c|c|c|c|c|c|c|c|}
\hline & \multicolumn{3}{|c|}{ Year $=1987$} & \multicolumn{4}{|c|}{ Year $=1988$} \\
\hline & \multicolumn{2}{|c|}{$\begin{array}{c}\text { Stayers } \\
\text { (1164 obs.) }\end{array}$} & $\begin{array}{l}\text { Movers } \\
\text { (115 obs.) }\end{array}$ & \multicolumn{2}{|c|}{$\begin{array}{c}\text { Stayers } \\
\text { (1274 obs.) }\end{array}$} & \multicolumn{2}{|c|}{$\begin{array}{l}\text { Movers } \\
\text { (155 obs.) }\end{array}$} \\
\hline & mean & (s.d. ) & mean (s.d.) & mean & $(\mathrm{s} . \mathrm{d})$. & mean & (s.d.). \\
\hline \multicolumn{8}{|l|}{ individual } \\
\hline age & 34.29 & $(10.35)$ & $25.89(7.85)$ & 34.64 & $(10.57)$ & 27.18 & $(8.52)$ \\
\hline single & 0.13 & & 0.12 & 0.14 & & 0.15 & \\
\hline single parent & 0.03 & & 0.04 & 0.04 & & 0.03 & \\
\hline extra & 0.12 & & 0.36 & 0.11 & & 0.27 & \\
\hline child<6yrs & 0.13 & & 0.13 & 0.13 & & 0.10 & \\
\hline \#children & 0.71 & & 0.48 & 0.70 & & 0.54 & \\
\hline other income & 30.82 & $(54.20)$ & $29.90(48.03)$ & 31.64 & $(55.22)$ & 26.53 & $(48.38)$ \\
\hline \multicolumn{8}{|l|}{ spouse } \\
\hline age & 38.31 & $(9.70)$ & $31.91 \quad(6.77)$ & 38.54 & $(9.78)$ & 33.66 & $(8.66)$ \\
\hline employed & 0.92 & & 0.96 & 0.92 & & 0.94 & \\
\hline hours worked & 38.60 & $(14.76)$ & $37.45(12.76)$ & 38.56 & $(14.94)$ & 38.53 & $(12.02)$ \\
\hline income & 543.81 & $(279.46)$ & $509.29 \quad(223.27)$ & 551.69 & $(304.28)$ & 540.65 & $(286.85)$ \\
\hline \multicolumn{8}{|l|}{ region } \\
\hline north & 0.09 & & 0.08 & 0.10 & & 0.08 & \\
\hline east & 0.22 & & 0.17 & 0.21 & & 0.19 & \\
\hline south & 0.25 & & 0.24 & 0.24 & & 0.23 & \\
\hline unempl. & 14.30 & $(1.92)$ & $14.22(1.97)$ & 9.69 & $(1.65)$ & 9.61 & $(1.58)$. \\
\hline
\end{tabular}

Note: stayers are women who stay in the same job, while movers are women who change job. The variable 'single' is a dummy for a woman living on her own, while the variable 'extra' is a dummy for a single woman living with others. 'Child<6yrs' is a dummy for having a child younger than 6 years old, '\#children' gives the number of children and 'other income' gives net other income in Dfl. per week. The variables under the heading spouse are only defined for married women, and give the characteristics of the spouse. 'Unempl.' gives the unemployment rate in percentage of the 'provincie' in which the woman lives.

with $D_{i t}$ a vector of typical labour supply variables, like number of children and other income, $\theta$ a parameter vector, and $\xi_{i}$ and $\xi_{i t}$ an individual effect and an random term, respectively.

It is a key issue of the empirical analysis to identify the coefficients in the latent variable equation, as well as the coefficients in the job mobility, hours adjustment and measurement equations. If identification of these coefficients is not possible, the question whether or not 
there is an indirect influence of socioeconomic variables via some latent variable on job mobility and hours adjustment cannot be solved. Generally speaking, to be able to identify and estimate the model we will take a random effects - simulated maximum likelihood approach. For details on identification and estimation, see Appendices A and B.

\section{Data}

From the October waves of the 1987, 1988 and 1989 Dutch Socio-Economic Panel (DSEP) we select women who work in at least two consecutive years. In total we are left with 1642 observations, of which 1063 are observed in all three years, 216 are only observed in the first two years, and 363 are only observed in the last two years. As the timing of the exogenous variables in the model is always at time t, table 2 shows these variables for the years 1987 and 1988 by job mobility. From this table it is clear that the job-movers are on average younger, are more often not married, have on average less children, and are more often living in the western part of the country, which is more urbanised. For the women who are married, the characteristics of their husbands do not differ very much between movers and stayers.

Table 3 shows the cross tabulation between satisfaction with working hours, $s_{i t}$, and the change in actual working hours. It reveals a strong dependence between the two, which seems stronger for the movers than for the stayers. Women who claim that they want to work less (more), have a relatively higher probability of working less (more) next year. This result is a reconfirmation of Euwals et al. (1998). The open question is to what extent the women are able to adjust according to their preferences within and between jobs.

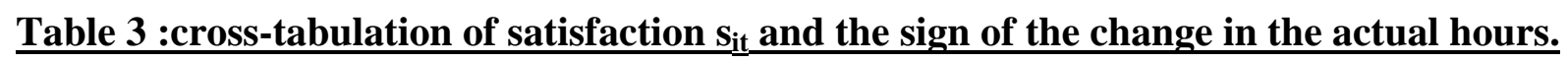

\begin{tabular}{|c|c|c|c|c|c|c|}
\hline & \multicolumn{3}{|c|}{ Stayers } & \multicolumn{3}{|c|}{ Movers } \\
\hline & $S_{i t}=-1$ & $\underline{S}_{i t}=0$ & $S_{i t}=1$ & $S_{i t}=-1$ & $S_{i t}=0$ & $S_{i t}=1$ \\
\hline$h a_{i t+1}-h a_{i t}<0$ & 33.7 & 21.0 & 16.0 & 53.2 & 24.7 & 2.4 \\
\hline$h a_{i t+1}-h a_{i t}=0$ & 47.1 & 56.5 & 39.2 & 27.7 & 26.9 & 7.3 \\
\hline \multirow[t]{2}{*}{$h a_{i t+1}-h a_{i t}>0$} & 19.2 & $\underline{22.4}$ & $\underline{44.8}$ & 19.1 & $\underline{48.4}$ & 90.2 \\
\hline & 100.0 & 100.0 & 100.0 & 100.0 & 100.0 & 100.0 \\
\hline observations & 469 & 1772 & 194 & 47 & 182 & 41 \\
\hline
\end{tabular}


Table 4: results of basic model

\begin{tabular}{|c|c|c|c|c|c|c|c|c|}
\hline & $\begin{array}{c}\text { job m } \\
\text { (equat } \\
\text { par. }\end{array}$ & $\begin{array}{l}\text { bility } \\
\text { on 1) } \\
\text { (s.e.) }\end{array}$ & $\begin{array}{l}\text { hours } \\
\text { (equat } \\
\text { par. }\end{array}$ & $\begin{array}{l}\text { adjustment } \\
\text { ion 2) } \\
\text { (s.e.) }\end{array}$ & & $\begin{array}{l}\text { desire } \\
\text { (equat } \\
\text { par. }\end{array}$ & $\begin{array}{l}\text { d hours } \\
\text { ions } 3,4 \text { ) } \\
\text { (s.e.) }\end{array}$ & \\
\hline constant & -0.21 & $(0.44)$ & -0.01 & $(0.97)$ & | & 45.12 & $(3.84)$ & \\
\hline hours (week) & & & & & | & & & $\underline{\text { individual }}$ \\
\hline $1-12$ hours & -1.28 & $(0.43)$ & -0.23 & $(1.84)$ & | & -0.47 & $(0.12)$ & age \\
\hline 13-27 hours & -1.13 & $(0.32)$ & 1.05 & $(1.14)$ & | & -8.88 & $(6.21)$ & married \\
\hline $28-37$ hours & -0.54 & $(0.29)$ & 0.60 & $(1.05)$ & | & -5.48 & $(2.65)$ & child<6yrs \\
\hline 38-39 hours & -0.23 & $(0.29)$ & 0.69 & $(1.25)$ & | & -0.23 & $(0.97)$ & \#children \\
\hline $41-90$ hours & 0.19 & $(0.50)$ & -0.79 & $(1.26)$ & | & 0.03 & $(1.41)$ & other income/10 \\
\hline region & & & & & | & & & spouse \\
\hline north & -0.08 & $(0.32)$ & & & | & 0.00 & $(0.01)$ & age \\
\hline east & -0.14 & $(0.23)$ & & & | & 0.03 & $(0.04)$ & income/10 \\
\hline south & -0.14 & $(0.21)$ & & & | & -1.94 & $(5.74)$ & employed \\
\hline unempl. & -0.03 & $(0.03)$ & & & | & 0.01 & $(0.09)$ & hours worked \\
\hline struc. par. & & & & & | & & & struc. par. \\
\hline$\beta^{p}\left(h^{*}-h a>0\right)$ & 0.05 & $(0.02)$ & & & | & 0.26 & $(0.02)$ & $\lambda$ \\
\hline$\beta^{\mathrm{n}}\left(\mathrm{h} \mathrm{d}^{*}-\mathrm{ha}<0\right)$ & 0.05 & $(0.02)$ & & & | & & & \\
\hline$\delta_{s}^{p}\left(h d^{\star}-h a>0\right)$ & & & 0.16 & $(0.07)$ & | & & & \\
\hline$\delta_{s}^{n}\left(h d^{*}-h a<0\right)$ & & & 0.12 & $(0.04)$ & | & & & \\
\hline$\delta_{\mathrm{m}}^{\mathrm{p}}\left(\mathrm{hd} \mathrm{d}^{\star}-\mathrm{ha}>0\right)$ & & & 0.75 & $(0.09)$ & | & & & \\
\hline$\delta_{\mathrm{m}}^{\mathrm{n}}\left(\mathrm{h} \mathrm{d}^{\star}-\mathrm{ha}<0\right)$ & & & 0.34 & $(0.11)$ & | & & & \\
\hline variances & & & & & | & & & variances \\
\hline$\sigma \_\varepsilon_{i t}$ & 1.00 & & 6.23 & $(0.11)$ & | & 5.24 & $(0.14)$ & $\sigma \_\varepsilon_{i t}$ \\
\hline$\sigma \_\varepsilon_{\mathrm{i}}$ & 0.00 & & & & | & 0.04 & $(1.37)$ & $\sigma \_\varepsilon_{\mathrm{i}}$ \\
\hline correlations & & & & & 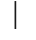 & & & \\
\hline$\rho \_\varepsilon^{q} \varepsilon^{*}$ & & & -0.02 & $(0.11)$ & | & 0.05 & $(0.09)$ & $\rho \_\varepsilon^{q} \varepsilon^{*}$ \\
\hline$\rho \_\varepsilon^{\mathrm{a}} \varepsilon^{\mathrm{d}}$ & & & & & & -0.06 & $(0.03)$ & $\rho \varepsilon^{\mathrm{a}} \varepsilon^{\mathrm{d}}$ \\
\hline
\end{tabular}

Note: the variances of $\varepsilon_{i}^{q}$ is restricted to zero, as in the ML-procedure it converged to zero. 
Table 5: results of proxy variable model

\begin{tabular}{|c|c|c|c|c|c|}
\hline & job mo & bility & hours a & djustment & \\
\hline & par. & (s.e.) & par. & (s.e.) & \\
\hline constant & -0.68 & $(0.16)$ & -1.40 & $(0.39)$ & | \\
\hline & & & & & | \\
\hline hours (week) & & & & & | \\
\hline $1-12$ hours & -0.27 & $(0.11)$ & 3.76 & $(0.56)$ & I \\
\hline 13-27 hours & -0.63 & $(0.11)$ & 2.47 & $(0.50)$ & | \\
\hline 28-37 hours & -0.34 & $(0.11)$ & 1.22 & $(0.50)$ & | \\
\hline 38-39 hours & -0.16 & $(0.12)$ & 0.90 & $(0.59)$ & | \\
\hline 41-90 hours & -0.33 & $(0.19)$ & -2.17 & $(0.49)$ & | \\
\hline & & & & & | \\
\hline region & & & & & | \\
\hline north & -0.10 & $(0.13)$ & & & | \\
\hline east & -0.13 & $(0.09)$ & & & I \\
\hline south & -0.15 & $(0.09)$ & & & 1 \\
\hline unempl. & -0.02 & $(0.01)$ & & & | \\
\hline & & & & & | \\
\hline struc. par. & & & & & | \\
\hline$\beta^{p}(\mathrm{hd}-\mathrm{ha}>0)$ & 0.05 & $(0.02)$ & & & | \\
\hline$\beta^{\mathrm{n}}(\mathrm{hd}-\mathrm{ha}<0)$ & 0.02 & $(0.02)$ & & & | \\
\hline$\delta_{s}^{p}(h d-h a>0)$ & & & 0.24 & $(0.04)$ & I \\
\hline$\delta_{s}{ }^{n}(h d-h a<0)$ & & & 0.07 & $(0.02)$ & I \\
\hline$\delta_{m}^{p}(h d-h a>0)$ & & & 0.62 & $(0.04)$ & | \\
\hline$\delta_{\mathrm{m}}^{\mathrm{n}}(\mathrm{hd}-\mathrm{ha}<0)$ & & & 0.66 & $(0.06)$ & | \\
\hline & & & & & | \\
\hline variances & & & & & 1 \\
\hline$\sigma_{-} \varepsilon_{\mathrm{it}}$ & 1.00 & & 6.66 & $(0.05)$ & | \\
\hline$\rho \_\varepsilon^{\mathrm{a}} \varepsilon^{\mathrm{d}}$ & & & 0.21 & $(0.03)$ & 1 \\
\hline
\end{tabular}

\section{Results}

This section first discusses the results using the model from section 4 . The section then moves on to a sensitivity analysis with respect to the sample selection criteria. One might suspect that the inclusion of certain groups of women, like students, affects the results in a significant way. The last part of the section discusses the results of a so-called proxy variable model, that is to say that we assume that the true and observed desired hours coincide. 


\section{$\underline{\text { Basic model }}$}

Table 4 shows the results for the basic model. We first discuss the results on the desired working hours, e.g. equations 3 and 4. Age has an impact on the number of desired working hours, younger women want to work significantly more hours than older women. Note that we can interpret this as an age-effect, as we have panel data and correct for individual effects. On the other hand, the time-dimension of our data is small and the individual effect turns out to be insignificant. Some caution is therefore still required in the interpretation of the age-effect. We find a clear significantly negative result on having a child younger than 6 years old. A remarkable result is that for married women, the husband's individual and job characteristics do not have a significant impact on the desired hours. In the basic model, the individual and husband's characteristics serve as exclusion restrictions; they are not included in the jobmobility and hours adjustment equation. A Wald-test on these variables shows that they have a jointly significant impact (test-statistic $=59.1$, critical value $\chi_{9 ; 0.05}^{2}=16.9$ ).

The effect of true desired hours on observed desired hours is determined by the parameter $\lambda$, which is equal to 0.26 and which is highly significant. The effect of the actual working hours $h a_{i t}$ on the observed desired hours, which is $(1-\lambda)$, seems large. An explanation for this large effect is that besides an anchoring effect, actual working hours also partly represent individual preferences. Off course we might have modelled this explicitly, but we would have needed exclusion restrictions for actual working hours. As these are hard to find in the data at hand, we leave this problem as it is.

Next we discuss the results on job-mobility, i.e. equation 1. The number of actual working hours at time $t$ has a significant impact on the probability to change job; woman who work few hours (1 to 27$)$ are less likely to change job. The deviation between the desired and actual working hours $h d_{i t}{ }^{*}-h a_{i t}$ also has a significant impact. This effect turns out to be monotonic; a woman who wants to work many hours ( $h d_{i t}{ }^{*}$ large) has a relative large probability to change job. In some way this is counter-intuitive, as one might expect that the probability to change job should be relatively low in the case that desired working hours are close to actual working hours (so $\beta^{n}$ should be negative). An explanation for this result is that the desired working hours might be positively correlated with ambition, which in turn might be positively correlated with changing job. As our data does not give measures on individual ambitions, we cannot make any statements on this potential bias. 
A problem for the job-mobility equation is to find reasonable exclusion restrictions. In our empirical analysis we apply a strategy which is used in the labour supply literature to model involuntary unemployment; we use regional variables to represent the impact of regional labour demand. See, for instance, Blundell et al. (1987). The underlying assumption for this analysis is that regional characteristics, e.g. labour demand, have an impact on the chances to change job, but have no effect on labour supply. Unfortunately, the regional variables do not have a significant impact on the probability to change job, a Wald-test gives an insignificant impact (test-statistic $=1.6$, critical value $\chi_{4 ; 0.05}^{2}=9.5$ ). So the correction for the endogeneity of changing job in the hours adjustment equation is only based on the distributional assumption. Comparable results on job-mobility are to the author's knowledge not available, as most of the literature on job-mobility uses data on displaced workers. See, for an example, Gibbons and Katz (1991).

The central results of the empirical analysis are on the adjustment of working hours, e.g. equation 2. Table 4 shows that the number of working hours at time $t$ has no significant impact on the rate of adjustment. The impact of the deviation between the desired and the actual working hours $h d_{i t}{ }^{*}-h a_{i t}$ is split up for women who want to work fewer and for women who want to work more hours per week. For women who stay in the same job, this does not make a difference; both groups have an average adjustment rate of about 14 percent. For women who change job, the difference between the two groups is substantial; women who want to work fewer hours achieve an average adjustment rate of 30 percent, while women who want to work more hours achieve an average adjustment rate of 80 percent. So the conclusion from these results is that working hours are relatively inflexible within jobs, while job-mobility is a means of hours adjustment mainly for women who want to work more hours.

The variances of the idiosyncratic random terms $\left(\varepsilon_{i t}{ }^{a}, \varepsilon_{i t}{ }^{d}\right)$ are precisely estimated, and seem to have a reasonable size of about 6 hours per week. In contrast, the variance of the individual effect is estimated quite imprecisely. This might be due to the short time-dimension of the panel; significant individual effects are a common finding in the labour supply literature. The estimated correlation coefficients between the idiosyncratic random terms are also quite imprecisely estimated. The negative correlation between the idiosyncratic terms of the hours adjustment equation and the desired hours equation is in itself counter-intuitive. One would expect that an unobservable leading to a high number of desired working hours, also leads to a relatively high adjustment in working hours, which would imply a positive correlation. 


\section{$\underline{\text { Sensitivity analysis }}$}

The conclusion of the basic model is that specially job-changers who want to work more hours per week are able to realize high adjustment rates. One might suspect that this is a result of job-search behaviour of women who work few hours per week, but want a full-time job. To investigate this, we do some sensitivity analyses by excluding students from the sample, and by excluding women who work less than 20 hours per week from the sample. The idea of excluding the students is that they mainly have small jobs, and that after finishing their education many start to work full-time. Re-estimations by using the sub-samples excluding these groups show that only part of the large adjustment of job-changers who want to work more hours is explained by job-search behaviour; for both sub-samples the average adjustment rate stays relatively large, about 60 percent.

\section{Proxy variable model}

Table 5 shows the results of the proxy variable model, which means that we approximate true desired hours by substituting observed desired hours. Note that the estimation results therefore might be biased due to measurement error. A clear difference with the results of the basic model is that the standard errors decrease substantially, leading to more significant results. The regional variables in the job mobility equation are still insignificant (Wald-teststatistic $=8.0$, critical value $\chi_{4 ; 0.05}^{2}=9.5$ ), but in the hours adjustment equation actual working hours are strongly significant. Most important is the impact of the deviation between desired and actual working hours in the hours adjustment equation. For the women who stay in the same job, there is now a substantial difference between the ones who want to work more hours (with an average adjustment of 24 percent), and the ones who want to work fewer hours (with an average adjustment of 7 percent). For women who change job there is hardly a difference between these two groups; both have an average adjustment of about 65 percent. These results are in sharp contrast to the results of the latent variable model.

\section{Conclusions}

In this paper we measure the flexibility of working hours within jobs, and measure to what extent job mobility is a means of working hours adjustment. We do this by relating subjective information on individual's preferences to realized adjustments in working hours over time. 
By formulating a latent variable model for the preferred working hours, and by using the subjective information on the preferences to identify the model, we are able to get point estimates on the flexibility of working hours within and between jobs. This is an improvement over Altonji and Paxson (1986, 1992) and Matinez-Granado (1999), who are only able to conclude on the flexibility of working hours within jobs, relative to the adjustments between jobs. We take the potential endogeneity of both the subjective information and job mobility into account. Based on a sample of women who are employed in at least two consecutive years in the Dutch Socio Economic Panel (1987-1989), we find a low flexibility of working hours within jobs. For both women who want to work more per week and women who want to work fewer hours per week, the average adjustment rate of working hours within jobs is about 14 percent. For women who change job and who want to work more hours per week, we find an average adjustment rate in working hours of about 80 percent. For women who want to work fewer hours, job mobility leads to a substantially lower adjustment in working hours of about 30 percent.

In terms of the flexibility of working hours, the Dutch labour market is an interesting one; already for several decades the share of part-time employment is among the largest of EC and OECD countries. In the time period under consideration in this paper, the late 1980s, the share of part-time employment among women was about 50 percent. The data from the Dutch Socio Economic Panel shows that the working hours of employed women was reasonably even distributed. This means that if we want to consider flexibility of working hours within jobs, the Dutch labour market is a good candidate to study. The empirical analysis in this paper however shows that the average hours adjustment within jobs in the preferred direction are small in the Netherlands, at least in the late 1980s. The empirical evidence from this paper therefore supports the intuitively obvious conjecture that working hours cannot be chosen freely within jobs. 


\section{Literature}

Altonji, J. and C. Paxson (1986), "Job Characteristics and Hours of Work" in Research in Labor Economics, Vol. 8, ed. R. Ehrenberg, pp. 1-55, Greenwich: Westview Press. Altonji, J. and C. Paxson (1992), “Labor Supply, Hours Constraints and Job Mobility”, Journal of Human Resources, Vol. 27, pp. 256-278.

Ben-Akiva, M., J. Walker, A. T. Bernardino, D. A. Gopinath, T. Morikawa, and A. Polydoropoulou (1998), "Integration of Choice and Latent Variable Models", Manuscript, MIT.

Ben-Akiva, M., A. Börsch-Supan, D. Bolduc, P. Delquié, T. Gärling, D. Gopinath, O. Larichev, D. McFadden, T. Morikawa, A. Poydoropoulou, and V. Rao (1999), "Preference Elicitation and Modeling Methods", Manuscript, MIT.

Blundell, R., J. Ham, C. Meghir (1987), "Unemployment and Female Labour Supply”, The Economic Journal (conference papers), Vol. 97, pp. 44-64.

Börsch-Supan, A., R. Euwals, and A. Eymann (1999), "Portfolio Choice with Behavioral Decision Mechanisms", SFB 504 discussion paper, No. 99-37.

Börsch-Supan, A., D. McFadden, R. Schnabel (1993), "Livings Arrangements: Health and Wealth Effects”, NBER Working Paper, No. 4398.

Dickens, W. and S. Lundberg (1993), "Hours Restrictions and Labor Supply", International Economic Review, Vol. 34, pp. 169-192.

Euwals, R., B. Melenberg, A. van Soest (1998), “Testing the Predictive Value of Subjective Labour Supply Data”, Journal of Applied Econometrics, Vol. 13, pp. 567-585.

Gibbons, R. and L. Katz (1991), "Layoffs and Lemons”, Journal of Labor Economics, Vol. 9, pp. 351-380.

Gourieroux, C. and A. Monfort (1993), "Simulation Based Inference: a Survey with Special Reference to Panel Data", Journal of Econometrics, Vol. 59, pp. 5-34. 
Ham, J.(1982), "Estimation of a Labour Supply Model with Censoring Due to Unemployment And Underemployment", Review of Economic Studies, Vol. 49, pp. 333-354.

Juster, T. (1964), “Anticipations and Purchases", Princeton, Princeton University Press.

Matinez-Granado, M. (1999), “Testing Labour Supply and Hours Constraints”, Manuscript, Universidad Carlos III de Madrid.

Moffit, R. (1982), “Tobit Models, Hours of Work and Institutional Constraints”, Review of Economics and Statistics, Vol. 64, pp. 510-515.

Van Soest, A., I. Woittiez, A. Kapteyn (1990), “Labor Supply, Income Taxes and Hours Restrictions in the Netherlands", Journal of Human Resources, Vol. 25, pp. 517-557. 


\section{A. Identification}

A key issue of the empirical analysis in this paper is to identify the coefficients of the true desired hours equation, as well as the coefficients of job mobility, hours adjustment and measurement equations. If identification is not possible, the question whether or not there is an indirect influence of socioeconomic variables via some latent variable on job mobility and hours adjustment cannot be solved. This appendix discusses the assumptions to identify the model. The first assumption we make:

\section{(A.1) The vector of individual and idiosyncratic terms $\left(\varepsilon_{i}^{q}, \varepsilon_{i t}{ }^{q}, \varepsilon_{i t}{ }^{a}, \varepsilon_{i}{ }^{d}, \varepsilon_{i t}{ }^{d}, \xi_{i}, \xi_{i t}\right)$ is i.i.d. multivariate normally distributed.}

A first remark on this assumption is that it implies that we will apply maximum likelihood. An alternative estimation procedure that would not need a distributional assumption is the Generalized Method of Moments. This method would be hard to apply for this system of equations, and it is beyond the scope of this paper. A second remark on the assumption is that we take a random effects approach. This implies that we assume that the individual effects are uncorrelated with the exogenous variables. An alternative approach would be to assume fixed effects. But again, it would be hard to apply and it is beyond the scope of the paper.

In latent variables models it is often necessary to restrict the variances of some of the random terms to identify the model. See, for instance, the discussion in Börsch-Supan et al. (1999). To illustrate the point for this paper, we substitute equation (4) in the equations (1) to (3):
(1') $Q_{i t}{ }^{*}=X_{i t}{ }^{\prime} \alpha+f\left(\left(D_{i t}{ }^{\prime} \theta-h a_{i t}\right)+\left(\xi_{i}+\xi_{i t}\right) ; \beta\right)$
$+\varepsilon_{i}^{q}+\varepsilon_{i t}^{q}$
(2') $\Delta h a_{i t}=Z_{i t}{ }^{\prime} \gamma+g\left(\left(D_{i t}{ }^{\prime} \theta-h a_{i t}\right)+\left(\xi_{i}+\xi_{i t}\right) ; \delta_{i t}\right)$
$+\varepsilon_{i t}{ }^{a}$
(3') $h d_{i t}=\lambda D_{i t}{ }^{\prime} \theta+(1-\lambda) h a_{i t}$
$+\left(\varepsilon_{i}^{d}+\lambda \xi_{i}\right) \quad+\left(\varepsilon_{i t}{ }^{d}+\lambda \xi_{i t}\right)$

The resulting equations are not that straightforward to interpret, as in equations ( $\left.1^{\prime}\right)$ and (2') the random terms $\left(\xi_{i}, \xi_{i t}\right)$ mix up with each other and with the exogenous variables. But the equations clearly illustrate the point that the random terms $\left(\xi_{i}, \xi_{i t}\right)$ show up in the error terms of these equations. So it is clear that the model is under-identified, and that restrictions on the 
(co-)variances are necessary. A first thing that becomes apparent is that covariances between $\left(\xi_{i}, \xi_{i t}\right)$ and the other random terms are not identified. Therefore the following assumption is necessary:

(A.2) The random terms in the latent variable equation, $\xi_{i}$ and $\xi_{i t}$, are uncorrelated with the other random terms.

The parameters $\beta, \delta$ and $\lambda$ are identified, as they determine the effect of the actual working hours in the equations $\left(1^{\prime}\right)$ and $\left(3^{\prime}\right)$. As we assume that there is no individual effect in the hours adjustment equation, we have five observed variances to identify the variances of the seven error terms $\left(\varepsilon_{i}^{q}, \varepsilon_{i t}{ }^{q}, \varepsilon_{i t}{ }^{a}, \mathcal{E}_{i}{ }^{d}, \mathcal{E}_{i t}{ }^{d}, \xi_{i}, \xi_{i t}\right)$. As in our estimation strategy we will formulate the joint distribution of $\left(\varepsilon_{i t}{ }^{q}, \varepsilon_{i t}{ }^{a}, \varepsilon_{i t}{ }^{d}\right)$, we impose restrictions in terms of $\left(\varepsilon_{i}^{d}, \varepsilon_{i t}{ }^{d}\right)$. Furthermore, the job-mobility equation is binary choice, so in this equation an extra restriction is needed. It is common in the literature to restrict the variance to one. Therefore we impose the following assumptions:

(A.3) $V\left(\xi_{i t}\right)=\sigma_{-}^{2} \varepsilon_{i t}{ }^{d}, V\left(\xi_{i}\right)=\sigma_{-}^{2} \varepsilon_{i}{ }^{d}$, and $V\left(\varepsilon_{i t}{ }^{q}\right)=1$

Strictly speaking the model is identified on the basis of the normality assumption (A.1) and the restrictions on the variances $(A .2, A .3)$. But as identification on the basis of distributional assumptions only is quite weak, we additionally impose the following exclusion restrictions:

(A.4) There will be at least one exogenous variable specific to the job-mobility and to the latent variable equation. 


\section{B. Estimation}

The estimation method we use in this paper will be simulated maximum likelihood. The likelihood contribution of an individual $\mathrm{i}$ at time $\mathrm{t}$ takes following form (in case of no job mobility, $Q_{i t}=0$ ):

(B.1) $\Lambda_{i t}=P\left(Q_{i t}=0, \Delta h a_{i t}=., h d_{i t}=\right.$. $)$

$=P\left(\varepsilon_{i t}{ }^{q}<., \varepsilon_{i t}{ }^{a}=., \varepsilon_{i t}{ }^{d}=. \mid \varepsilon_{i}^{q}, \varepsilon_{i}^{d}, \xi_{i}, \xi_{i t}\right) P\left(\varepsilon_{i}^{q}, \varepsilon_{i}^{d}, \xi_{i}, \xi_{i t}\right)$

$=P\left(\varepsilon_{i t}{ }^{q}<. \mid \varepsilon_{i t}{ }^{a}, \varepsilon_{i t}{ }^{d}, \varepsilon_{i}^{q}, \varepsilon_{i}^{d}, \xi_{i}, \xi_{i t}\right) P\left(\varepsilon_{i t}{ }^{a}=., \varepsilon_{i t}{ }^{d}=. \mid \varepsilon_{i}^{q}, \varepsilon_{i}^{d}, \xi_{i}, \xi_{i t}\right) P\left(\varepsilon_{i}^{q}, \varepsilon_{i}^{d}, \xi_{i}, \xi_{i t}\right)$

$=\iiint \int P\left(\varepsilon_{i t}{ }^{q}<. \mid \varepsilon_{i t}{ }^{a}, \varepsilon_{i t}{ }^{d}, \varepsilon_{i}^{q}, \varepsilon_{i}{ }^{d}, \xi_{i}, \xi_{i t}\right) P\left(\varepsilon_{i t}{ }^{a}=., \varepsilon_{i t}{ }^{d}=. \mid \varepsilon_{i}^{q}, \varepsilon_{i}^{d}, \xi_{i}, \xi_{i t}\right) P\left(\varepsilon_{i}^{q}, \varepsilon_{i}{ }^{d}, \xi_{i}, \xi_{i t}\right) d \varepsilon_{i}^{q} d \varepsilon_{i}^{d} d \xi_{i} d \xi_{i t}$

The simulated form of this likelihood contribution is:

$$
\Lambda_{i t}{ }^{s}=(1 / R) \sum_{r=1, . ., R} P\left(\varepsilon_{i t}{ }^{q}<. \mid \varepsilon_{i t}{ }^{a}, \varepsilon_{i t}{ }^{d}, \mathcal{E}_{i r}{ }^{q}, \mathcal{\varepsilon}_{i r}{ }^{d}, \xi_{i r}, \xi_{i t r}\right) P\left(\varepsilon_{i t}{ }^{a}=., \varepsilon_{i t}{ }^{d}=. \mid \varepsilon_{i r}{ }^{q}, \mathcal{E}_{i r}{ }^{d}, \xi_{i r}, \xi_{i t r}\right)
$$

with $\left(\mathcal{E}_{i r}{ }^{q}, \mathcal{E}_{i r}{ }^{d}, \xi_{i r}, \xi_{i t r}\right)$ for $r=1, \ldots, R$, being independent draws from the normal distribution, in which we assume that the covariances are zero. Provided that $R$ tends to infinity at a fast enough rate with the number of observations, this method is asymptotically equivalent to exact maximum likelihood, see Gourieroux and Montfort (1993). In this paper we take $R=50$. 